Letter to the Editor

\title{
Moral cognition and homicide amongst forensic patients with schizophrenia and schizoaffective disorder: A cross-sectional cohort study
}

\author{
Ken O'Reilly ${ }^{\mathrm{a}, \mathrm{b}}$, Paul O'Connell ${ }^{\mathrm{a}, \mathrm{b}}$, Aiden Corvin ${ }^{\mathrm{a}, \mathrm{b}}$, Danny O'Sullivan ${ }^{\mathrm{b}}$, Ciaran Coyle ${ }^{\mathrm{b}}$, Ronan Mullaney ${ }^{\mathrm{a}, \mathrm{b}}$, \\ Padraic O'Flynn ${ }^{\text {b }}$, Katie Grogan ${ }^{\text {b }}$, Melanie Richter ${ }^{\text {b }}$, Harry Kennedy a,b,* \\ a The Department of Psychiatry, Trinity College Dublin, Ireland \\ b The National Forensic Mental Health Service, The Central Mental Hospital, Dundrum, Dublin 14, Ireland
}

\section{A R T I C L E I N F O}

\section{Article history:}

Received 22 November 2016

Received in revised form 7 July 2017

Accepted 9 July 2017

Available online $\mathrm{xxxx}$

Keywords:

Schizophrenia

Moral cognition

Homicide

Neurocognition

Violence

Risk assessment

\begin{abstract}
A B S T R A C T
Forensic patients with schizophrenia who had carried out a homicide scored higher on a measure of moral cognition (MFQ-30) than other violent patients. Neurocognitive impairment was associated with homicide by mediation via higher scores for in-group loyalty.
\end{abstract}

(c) 2017 Elsevier B.V. All rights reserved.

\section{Dear editor}

Moral cognition may play a paradoxical role in acts of homicide by patients with schizophrenia. There is an established literature on the psychology of moral cognition, including moral foundations theory (Haidt, 2007). Violence and homicide are rare in patients with schizophrenia although there is an association (Fazel et al., 2009). The mentalistic concept of legal insanity (an innocent intent) has been widely accepted for centuries. Both loss of contact with reality through delusions and hallucinations and confused moral reasoning are accepted mitigating and explanatory factors. Empirical evidence supports an association between violence and delusions and hallucinations (Coid et al., 2013; Keers et al., 2014; Ullrich et al., 2014) but the form and content of the associated moral reasoning has not been investigated. Understanding whether impaired neurocognitive ability and moral cognition in schizophrenia are associated with serious violence could have implications for risk assessment and treatment (O'Reilly et al., 2015).

We hypothesized that (a) higher scores on moral cognition measured by the Moral Foundations Questionaire-30 (MFQ-30) (Graham

* Corresponding author at: Professor Harry Kennedy, National Forensic Mental Health Service, Central Mental Hospital, Dundrum, Dublin 14, Ireland.

E-mail address: kennedh@tcd.ie (H. Kennedy). et al., 2011) could account for a significant amount of the variance in homicide outcomes amongst forensic patients with schizophrenia and schizoaffective disorder; (b) neurocognitive impairment might influence homicidal acts in this group by impairing moral cognition.

We carried out a cross-sectional national cohort study using multivariate analysis (MANOVA) to test associations between homicide and moral foundations (MFQ-30). All inpatients with a diagnosis of schizophrenia or schizoaffective disorder (SCID) and a history of violence were approached, 44 (22 homicide), 34 (19 homicide) of these were found Not Guilty by Reason of Insanity (NGRI). All gave informed consent. The MFQ-30 measures care-harm, fairness-reciprocity, in-grouployalty, authority-respect, purity-sanctity and two super-ordinate composite factors individualizing and binding (Graham et al., 2011). Neurocognition was assessed using the Matrics Consensus Cognitive Battery (MCCB) (Nuechterlein et al., 2008).

One-way MANOVA (Table 1) for all five foundations and the superordinate composites showed that patients who committed homicide scored significantly higher on the MFQ-30 (Pillai's trace 0.376 , $\mathrm{F}(5,38)=4.587, \mathrm{p}<0.002)$, specifically on in-group-loyalty, authority-respect and the binding factor. For the NGRI sub-sample one-way MANOVA showed that those who had committed homicide scored significantly higher on the overall model (Pillai's trace $0.472 ; \mathrm{F}(5,28)=$ 5.013, $\mathrm{p}<0.002$ ) and also on in-group-loyalty, authority-respect and the binding factor. 
Table 1

Mean (SD) comparisons for t-scores on MFQ-30 domains, comparing homicide and other violent groups.

\begin{tabular}{|c|c|c|c|c|c|c|c|c|c|c|}
\hline \multirow[t]{3}{*}{ MFQ-30 foundations and super-ordinate composites } & \multicolumn{7}{|l|}{ ANOVA } & \multicolumn{3}{|c|}{ Effect size d } \\
\hline & \multicolumn{2}{|c|}{ Other violence } & \multicolumn{2}{|c|}{ Homicide } & \multirow[t]{2}{*}{ F-statistic } & \multirow[t]{2}{*}{$\mathrm{p}$ value } & \multirow[t]{2}{*}{ Partial Eta squared } & \multirow[t]{2}{*}{$\mathrm{d}$} & \multicolumn{2}{|l|}{$95 \% \mathrm{CI}$} \\
\hline & Mean & S.D. & Mean & S.D. & & & & & Lower & Upper \\
\hline \multicolumn{11}{|l|}{ Total sample $n=44$} \\
\hline & $\mathrm{n}=22$ & & $\mathrm{n}=22$ & & & & & & & \\
\hline Care-harm & 25.09 & 3.59 & 25.00 & 4.53 & 0.005 & 0.942 & 0.000 & -0.022 & -0.613 & 0.569 \\
\hline Fairness-reciprocity & 23.36 & 3.44 & 23.09 & 3.37 & 0.070 & 0.792 & 0.002 & -0.079 & -0.670 & 0.512 \\
\hline Individualizing super-ordinate composite & 48.45 & 6.17 & 48.09 & 7.50 & 0.031 & 0.861 & 0.001 & -0.052 & -0.643 & 0.539 \\
\hline In-group-loyalty & 18.95 & 4.65 & 23.09 & 3.72 & 10.585 & 0.002 & 0.200 & 0.983 & 0.358 & 1.609 \\
\hline Authority-respect & 17.00 & 4.27 & 20.95 & 5.70 & 6.772 & 0.013 & 0.140 & 0.780 & 0.171 & 1.398 \\
\hline Purity-sanctity & 19.27 & 4.98 & 19.09 & 6.95 & 0.122 & 0.729 & 0.003 & 0.104 & -0.487 & 0.696 \\
\hline Binding super-ordinate composite & 55.22 & 11.77 & 63.95 & 14.79 & 4.686 & 0.036 & 0.100 & 0.653 & 0.047 & 1.26 \\
\hline \multicolumn{11}{|l|}{ NGRI sub-sample $\mathrm{n}=34$} \\
\hline & $\mathrm{n}=15$ & & $\mathrm{n}=19$ & & & & & & & \\
\hline Care- harm & 25.86 & 3.22 & 25.05 & 4.78 & 0.318 & 0.577 & 0.010 & -0.199 & -0.791 & 0.394 \\
\hline Fairness-reciprocity & 24.00 & 2.87 & 22.94 & 3.48 & 0.887 & 0.353 & 0.027 & -0.332 & -0.927 & 0.263 \\
\hline Individualizing super-ordinate composite & 49.86 & 5.23 & 48.00 & 7.84 & 0.627 & 0.434 & 0.019 & -0.279 & -0.873 & 0.315 \\
\hline In-group-loyalty & 17.73 & 4.51 & 23.00 & 3.65 & 14.174 & 0.001 & 0.307 & 1.285 & 0.635 & 1.934 \\
\hline Authority-respect & 16.66 & 4.53 & 20.63 & 5.94 & 4.565 & 0.040 & 0.125 & 0.752 & 0.140 & 1.363 \\
\hline Purity-sanctity & 18.80 & 5.96 & 19.78 & 7.24 & 0.182 & 0.673 & 0.006 & 0.148 & -0.444 & 0.740 \\
\hline Binding super-ordinate composite & 53.20 & 13.19 & 63.42 & 15.15 & 4.263 & 0.047 & 0.118 & 0.720 & 0.110 & 1.329 \\
\hline
\end{tabular}

Bold text indicates statistical significance.

To examine relationships between neurocognition, moral cognition and homicide we used mediation modelling (Hayes Process model 4; Hayes, 2013). Lower MCCB scores were related to homicide via an indirect mediation pathway with in-group-loyalty as mediator $(\beta=-0.0326$, $95 \% \mathrm{CI}-0.0860$ to -0.0072 ). Higher in-group loyalty scores were associated with homicide even after adjustment for MCCB (beta $=+0.2213$, $95 \% \mathrm{CI}+0.0467$ to +0.3958$)$. These effects were stronger for the NGRI subgroup.

This is the first study to demonstrate that moral cognitions as measured by the MFQ-30 are associated with homicide in forensic patients with schizophrenia and schizoaffective disorder accounting for $37.6 \%$ of the variance in homicide in the total sample, $47 \%$ of the variance in the NGRI sub-sample. Patients who committed homicide scored higher on in-group loyalty and authority. Moral cognition appears relevant to the study of serious violence in schizophrenia. This may be partly explained by the associated neurocognitive impairment in schizophrenia. Neurocognition had an effect on homicide that was mediated through the in-group loyalty foundation.

The MFQ-30 is a measure of dispositions. This is the first time it has been used in patients with schizophrenia. It remains to be shown that the moral cognitions identified here were the beliefs relevant to the acts of homicide, including delusions, hallucinations and emotions (Kennedy et al., 1992; Coid et al., 2013).

\section{Contributors}

Dr. O'Reilly and Prof Kennedy had full access to all of the data in the study and take responsibility for the integrity of the data and the accuracy of the data analysis. Study concept and design: O'Reilly, O'Connell and Kennedy. Acquisition of data: Coyle, O'Sullivan, O'Flynn, Grogan, Richter. Analysis and interpretation of data: O'Reilly, Corvin, Kennedy. Drafting of the manuscript: O'Reilly, O'Connell, Corvin, Mullaney, Coyle, O'Sullivan, O'Flynn, Grogan, Richter, Kennedy. Critical revision of the manuscript for important intellectual content: O'Reilly, O'Connell, Corvin, Mullaney, Coyle, O'Sullivan, O'Flynn, Grogan, Richter, 'Kennedy. Statistical analysis: O'Reilly, Kennedy. All authors have read and approved the final manuscript.

\section{Conflict of interest}

The authors declare no conflict of interest.

\section{Role of funding source}

This research received no specific grant from any funding agency, commercial or notfor-profit sectors. The work was carried out as part of the routine quality improvement programmes of the Health Service Executive's National Forensic Mental Health Service. The funding agency had no role in design and conduct of the study; in the collection, analysis, and interpretation of the data; or in the preparation, review, or approval of the manuscript.

\section{Acknowledgments}

The authors wish to acknowledge all of the patients who voluntarily gave up their time to participate in the study.

\section{References}

Coid, J.W., Ullrich, S., Kallis, C., Keers, R., Barker, D., Cowden, F., et al., 2013. The relationship between delusions and violence: findings from the East London first episode psychosis study. JAMA Psychiat. 70 (5), 465-471.

Fazel, S., Gulati, G., Linsell, L., Geddes, J.R., Grann, M., 2009. Schizophrenia and violence: systematic review and meta-analysis. PLoS Med. 6 (8), e1000120.

Graham, J., Nosek, B.A., Haidt, J., Iyer, R., Koleva, S., Ditto, P.H., 2011. Mapping the moral domain. J. Pers. Soc. Psychol. 101 (2), 366-385.

Haidt, J., 2007. The new synthesis in moral psychology. Science 316 (5827), 998-1002.

Hayes, A.F., 2013. Introduction to Mediation, Moderation, and Conditional Process Analysis: A Regression-Based Approach. Guilford Press, NY.

Keers, R., Ullrich, S., DeStavola, B.L., Coid, J.W., 2014. Association of violence with emergence of persecutory delusions in untreated schizophrenia. Am. J. Psychiatr. 171 (3), 332-339.

Kennedy, H., Kemp, L., Dyer, D., 1992. Fear and anger in delusional (paranoid) disorder: the association with violence. Br. J. Psychiatry 160 (4), 488-492.

Nuechterlein, K.H., Green, M.F., Kern, R.S., Baade, L.E., Barch, D.M., Cohen, J.D., et al., 2008. The MATRICS Consensus Cognitive Battery, part 1: test selection, reliability, and validity. Am. J. Psychiatr. 165 (2), 203-213.

O'Reilly, K., Donohoe, G., Coyle, C., O'Sullivan, D., Rowe, A., Losty, M., et al., 2015. Prospective cohort study of the relationship between neuro-cognition, social cognition and violence in forensic patients with schizophrenia and schizoaffective disorder. BMC Psychiatry 15 (1), 1.

Ullrich, S., Keers, R., Coid, J.W., 2014. Delusions, anger, and serious violence: new findings from the MacArthur Violence Risk Assessment Study. Schizophr. Bull. 40 (5), 1174-1181. 